\title{
Menace of Human Trafficking in Nepal
}

\author{
Kavita Thapa \\ Counsellor, D.A.V Public School, Sector-14, Gurugram \\ DOI: 10.29322/IJSRP.11.08.2021.p11605 \\ http://dx.doi.org/10.29322/IJSRP.11.08.2021.p11605
}

\begin{abstract}
Human Trafficking is one of the mostly committed crime in the world for the purpose of forced labour, sexual slavery or for sexual exploitation. Nepal is one of the world's most lucrative markets for human trafficking and women and girls make up the majority of all victims. Many are trafficked for sex work, domestic labour, entertainment sector or the illegal organ trade in India, Southeast Asia and the Gulf. Number of factors like unstable government, illiteracy, poor economic condition makes the women and girls more vulnerable to human trafficking but this pandemic has exacerbated these issues. Due to the covid-19 outbreak and subsequent lockdown affected almost all the areas. A number of research works have shown that the number of crimes such as domestic violence, sexual violence as well as human trafficking has increased as a result of low or no daily income. Studies conducted in the past show that the crime like human trafficking increases during the epidemics, that disrupt the livelihood of the common man. Human traffickers and brokers become active during the pandemic as the counter-trafficking activities collapse and it becomes easy to lure the vulnerable people in such situations. The objective of this paper is to understand the tendency of human trafficking, routes used for trafficking, major destination and transit countries, most affected areas and communities of Nepal, purpose of human trafficking, consequences of human trafficking and possible solutions and preventive measures to check the problem.
\end{abstract}

Index Terms- Human Trafficking, Nepal, Government, possible solutions, route, Consequences of trafficking, factors encouraging trafficking, purpose of trafficking, most affected area and community, destination countries, transit countries, Nepal Police.

\section{INTRODUCTION}

$\mathrm{N}$ epal the land of Lord Buddha is known for its fertile lands, forests and world tallest mountain i.e., Mount Everest. The population of Nepal is estimated to be around 26.5 million where female constitute $54.4 \%$. The status of the women remains poor even in the $21^{\text {st }}$ century. Even today majority of the women just look after the household and take care of the children. The males are the ones who take care of the financial expenses of the house. Due to this, women are not valued at the hands of their husband and family members because they are financially dependent to them.

Women are vulnerable to human trafficking due to caste discrimination, political and social discrimination.

According to the United Nations Protocol Human Trafficking is defined as is the recruitment, transportation, transfer, harbouring or receipt of persons, by means of the threat or use of force or other forms of coercion, of abduction, of fraud, of deception, of the abuse of power or of a position of vulnerability or of the giving or receiving of payments or benefits to achieve the consent of a person having control over another person, for the purpose of exploitation.

Human trafficking is considered to be the third largest crime throughout the world. The crime is managed so efficiently that it becomes difficult to trace out the networks and links.

Nepal is facing the serious problem of human trafficking for lucrative business of organ trafficking, sex trade, child labour and forced labour, forced marriage.

Porous international border, poor economic condition, illiteracy, unstable government are the major reasons of increasing cases of human trafficking.

Despite the mounting awareness and the laws for human rights, the occurrences of the crime are increasing day by day.

Globalization has opened new routes for these traffickers including the use of modern technology to spread their network to international borders. According to a UN report 2014 approximately 7,000 Nepalese women and girls are trafficked into India every year.

According to National Human Rights Commission 2020, $5 \%$ of Nepalese are highly vulnerable people,35,000 are sold every year for human trafficking to engage in difficult and danger foreign employments, adult entertainment and child labour activities.

This research work will be advantageous for policy makers, police personnel, potential victims, women activist, law enforcement committee and NGOs fighting against the human trafficking.

The research work revolves around the following questions:

- Tendency of human trafficking

- Route used for trafficking.

- Major Transit and Destination Countries.

- Most affected area and community.

- Factors encouraging the human trafficking.

- Purpose of human trafficking.

- Consequences of the trafficking.

- Possible solutions and preventive measure to check the problem.

\section{Methodology:}

This research is based on qualitative research approach. The primary sources of information are journals. The secondary sources are articles, documentary, report, talk shows and books. 


\section{LITERATURE REVIEW}

\section{History of human trafficking}

Trafficking of human originally started with the trend of slavery. In 1400's, people from Portuguese and Africa were transported to Europe to use them as slave. Women and young girl were forced to do labour for no or little pay.

History of trafficking in Nepal can be traced back during the Rana regime. Girls from the surroundings hills were brought to the Kathmandu Palaces. They were kept as housemaids, concubines, dancers, singers. They were called nani, rakhauti and ketishaya. Many studies showed that as the Rana regime collapsed in 1951, some rana families fled to India and took the housemaids along with them for luxury and sexual pleasure. But after sometime Ranas were running out of their financial expenses than they sold the housemaids in the brothels.

Later on, these prostitute women opened their own brothels in the cities and started to recruit women and girls from the areas of their origin. These women used to visit their families and support them financially and this attracted other girls into this business.

Another reason for high rate of Nepalese women being trafficked is due to heavy demands in the Indian market because of their fair complexion and it was safer to sell these girls than the local girls for prostitution.

The growth of carpet industry led to the increase in the internal and cross border trafficking of women and young children. Many children were enslaved in the factories where they were exploited and abused sexually and physically. The carpet factories became the transit centre for trafficking of girls and boys to India.

Other industries like garments, embroidering and brick kilns also employed large number of children and women. The risk of trafficking from these industries was also the same as of carpet factories.

Religious tradition in Nepal, particularly in the western parts of the country known as badini, jhuma and deuki leads to the exploitation of the girls. Deuki is an ancient custom practiced in the far western regions of Nepal where a young girl is offered to the local temple. Once they are offered to the temple, they are considered unfit for marriage and receive no money from their parents. They have to depend on the worshipers' monetary offerings to the temple. They have no skills or education to support themselves so they resort to survival sex, a form of prostitution in which sex is traded for basic necessities such as food, clothing and shelter. The practice of Deuki has been formally abolished by the Nepalese government but girls continue to become deukis. It is still prevalent mostly in districts like Baitadi, Kanchanpur, Dadeldhura, Doti and Bajura but these days with a changed namedevi system.

Jhuma is prevalent among the Sherpas, a Tibeto-Burman ethnic group living in the north of the country. A baby girl is offered to the monastery. She is not allowed to marry but men seek sexual relations with jhuma.

Badi is a hill dalit community in Nepal. Badi women works as prostitutes. Even though the government agreed to rehabilitate the Badi community and provide employment, but these assurances have been limited to papers alone. These old age tradition and customs make the women more vulnerable and become the easy targets for traffickers.
Another reason that makes the women and children more vulnerable to trafficking was the armed conflict between the CPN Maoists and the state of Nepal. Studies done by various organization showed that many displaced girls ended up in severely exploitative work such as in dance bars and cabin restaurants and faced sexual harassment along with exploitative work condition.

In Nepal the history of trafficking is also associated with the relation of economic business with India. The approval of open border between India and Nepal in 1980 tremendously increased the outflow of Nepalese migrant workers in India. Due to which women became the most vulnerable and fell into the honeytrap of the pimps by promising of a better life and opportunities in the cities in India.

Sex trafficking has become a lucrative business since pimps can make a huge money within a short period due to low start-up costs, minimal risks, high profits and large demand. The women from rural Nepal are deprived of empowerment and leadership skills. Illiteracy and no awareness are the major reasons of human trafficking in Nepal.

The government of Nepal has various law to combat the issue of human trafficking. Under the Human Trafficking Control Act of 1986, the Nepal government has clearly stated that transporting a person to foreign country with the intention of selling and forcing a woman into prostitution are punishable offences with imprisonment for up to 20 years.

They further implemented a ban on Nepali women below 30 years of age seeking going to gulf countries due to several reports that they face sexual abuse and exploitation as house helpers in those countries. The ban existed for a certain period, but because black market is so rampant in Nepal that the rules were broken and the agencies started allowing to transport. In implementing the ban without providing job opportunities in Nepal, the govt's actions increased the risk of women being transported illegally to the foreign country.

Human Right Watch (1995) stated that girls or women are trafficked not only for prostitution but also for other work like entertainment industry like bar, club, bonded labours, maid/servants.

Evans and Bhattrai (2000) reported that unsafe migration due to the discrimination faced by the women pushes them into the vulnerable situation and sometimes many of them become the victim of sex trafficking.

Bal KC \& et.al (2001) reported that the main root cause of trafficking was for prostitution. He further mentioned that sex trade is the main reason behind the rise of HIV among the sex workers.

KC et.al (2001) found that trafficked victims were from the different caste and ethnic groups but the Tamang children and women were highest in number because they constituted majority of workforce in the carpet factories in the Kathmandu valley. They were trafficked to Indian carpet factories located at Bhadohi, Mirzapur by the brokers from the carpet factories in Kathmandu. A National Report by Govind Subedi and et.al on trafficking and sexual abuse among street children in Kathmandu, Nepal (2002) explains the various reason for the human trafficking including illiteracy, poverty, family conflict, death of both the parents, lack of awareness, poor social condition, inadequate law and order 
enforcement. It was also mentioned in the report that India provides exit route to these traffickers.

Anna M. Troubnikoff (2003) had mentioned in her study that human trafficking is one of the fastest growing areas of international crime and the largest number of victims are from underdeveloped countries.

Michael L. Penn \& et.al (2003) reported that due to increase in demand of child sex by the paedophile tourists many children are trafficked into this business. Sex tourism industry continue to grow despite having more HIV cases because the paedophiles believe that sex with virgins will enable them to avoid AIDS.

According to Henrik and Simkhada (2004) traffickers used to lure the victim by making false promises, giving them money in advance and performing fake marriages.

Nair \& et.al (2005) talked about timely judicial intervention, effective laws are needed to combat the menace of trafficking.

Ali (2005) had mentioned in his study that females who are disowned by her husband and in-laws becomes an easy target for trafficking by the traffickers.

Huda (2006) stated that Nepalese have been lured by the traffickers that they will provide good life and job in the gulf countries and this led to unsafe and undocumented migration of Nepalese to those countries and later they might be the victim of trafficking.

Mukherjee and et.al (2008) reported that Nepalese girls and women are trafficked because they are lacking skills type of works, lack of awareness, migration and rejection by the husbands and sometimes rejection in the love also lead to the trafficking of the Nepalese to other countries.

P.M. Nair (2010) talked about the sensitization of vulnerable families. He further explains the mechanisms and methodologies of human trafficking.

Dottridge \& et.al (2012) Trafficking of adults always require force, deception and coercion, but when a third party moves or uses children in prostitution, pornography or removal of organs, force or coercion do not need to be present to deem these acts child trafficking.

In 2014 NHRC interviewed females who worked in the entertainment sector workplaces like massage parlour, dance bars and cabin restaurants found that $40-60 \%$ females were under the age of 19.

Nepal's National Human Rights Commission's (NHRC) report indicated that $78 \%$ of the identified victims of trafficking in 2017/2018 were female and 25\% were children.

A. Kumar (2019) reported that discrimination faced by the women is one of the reasons of trafficking. Further he added that Nepal's political instability is also responsible for the trafficking of Nepalese to other countries.

\section{Ways /Tendency of human trafficking:}

Women and girls are trafficked with a range of techniques depending on the situation. Most traffickers possess an in-depth knowledge of local culture, tradition, vulnerable households for the easy way out. Below are the common ways:

- Misuse of travel visas - Many women and young girls are trafficked by the traffickers in the name of travelling to the foreign countries.

- Fake marriage - Traffickers sometimes perform fake marriage with the victim in order to gain her trust. Later on, they sell them to the brothels in India or send them to the foreign land where they are exploited.

- Trafficking operates from third country - Traffickers operate from the third country out of Nepal. They operate trafficking rackets in the name of attractive employment opportunities.

- $\quad$ Misusing social media - Traffickers target the potential victims by using social media. Initially they send friend request. Once the friend request is accepted, they will keep on chatting and try to gain their trust. And later on, they perform marriage and sell them in the brothels or are trafficked to the gulf countries.

- Illegal organ transplant - Due to poverty in Nepal traffickers easily target the poor people to sell their kidneys in exchange of some money. Sometimes the traffickers arrange the fake travel and medical treatment papers and are easily brought to the Indian cities where the illegal organ transplantation take place.

- Foreign employment opportunities - Many young men and women are trafficked in the name of employment opportunities to the foreign land. They lure them by telling how the job will change their destiny and lifestyle.

- Settlement in Developed countries - Traffickers lure the prospective victim by promising them to help them to settle down in the developed countries like USA, UK, Australia etc.

- Involvement of Parents or family members - Sometimes traffickers search the prospectus victim and directly contact the parents or the family members like brother, uncle, aunt, brother -in -law, sister-in -law, step mother, step father or sometimes even the husband and are sold to the traffickers for few bucks.

- Administering of drugs - Women and girls are trafficked by giving them food laced with drugs which make them unconscious and by the time they gain their conscious they are very far away from their country surrounded by unknown faces and people speaking different language which they don't understand which make them more vulnerable and they have to follow what the traffickers wants and usually they are forced into prostitution.

- Cultural program - Sometimes traffickers traffic the young girls in the name of cultural program. In the year 2016-2017, Maiti Nepal, Birgunj Branch Office rescued 12 girls from Orchestra dance in Motihari and Bagaha of Bihar, India. The girls were first given training for one week. After that they were made to do erotic dance with naked body. They were made to stay in the hut. Sometimes the men used to come at night and abuse them.

- Quality education -The traffickers used to traffic young girls from the rural areas in the name of providing good education to them in the cities by gaining the trust of their parents.

- Entertainment sector- Many young girls/women are being trafficked to the countries like Malaysia, Tanzania, United Arab Emirates, Kenya, Bahrain in the name of working in a dance or disco bar. 
- $\quad$ Forging the documents- Traffickers trafficked the victim by increasing their age to make the passport and citizenship. The traffickers make arrangements with Ward Level and district Administration Office for issuing the citizenship certificate of under age children and issuing a passport.

\section{Routes used for trafficking:}

Nepal and India share an open border which spans about 1,000 kilometres on the south and south-west. The major transit points from Nepal to India include Pasupati Nagar (Ilam), Kakarbhitta (Jhapa), Biratnagar (Morang), Bhantabari (Saptari), Birgunj (Parsa), Bhairawa (Rupandehi), Nepalgunj (Banke) and Mahendra Nagar (Kanchanpur).

Nepalese women and girls are trafficked through these transit routes to not only India but to the various countries including China, Malaysia, South Korea, Sweden, Middle East, Sri Lanka and even to Africa also.

Major Transit and Destination Countries for trafficking: Following are the major transit countries:

- India

- Bangladesh

- Pakistan

- Sri Lanka

- Myanmar

- Thailand

- Singapore

- Hongkong

- Indonesia

- Kuwait

- Mexico

Following are the major destination countries and for what purpose the human trafficking takes place.

- USA- Nepalese people are smuggled to the USA through various transits. Upon arriving, they become the victims of forced labour.

- $\quad$ Europe - Males and females are trafficked to work in farms, domestic works, elderly care and adult entertainment.
- India - It is both a transit and destination country for human trafficking. People are trafficked for sexual exploitation, forced labour, organ harvesting, street begging and entertainment sectors. It is also one of the transit points for several countries. Traffickers use India's International airports and waterways from Chennai and Kolkata for trafficking.

- China and South Korea- Females are trafficked for forced marriage and sex industry.

- Japan- Trafficked people are forced to work in farms and adult entertainment sectors.

- Australia- Due to restricted work permit, students from the different parts of the world who come there to study become the victims of labour exploitation.

- Malaysia- Many Nepalese workers are forced to work on construction sites and factories on mere wages.

- Middle East (Syria, Kuwait, Iraq, UAE and Bahrain)Kuwait is both a transit and destination country for human trafficking. Nepalese women and girls are trafficked for forced domestic work and adult entertainment.

- Kenya- Mainly women are forced to work in adult entertainment.

- $\quad$ Nigeria and Morocco- Males and females are trafficked to work in security service and in cruise ships.

Most affected area, community and age group.

Traffickers trafficked the people from all parts of Nepal but following are the worst affected area:

- Nuwakot

- Sindhupalchowk

- Kavre

- Dhading

- Accham

- Rasuwa

- Pyuthan

Although girls and women are trafficked from every community but the most affected community is Janjati which consist of Rai, Limbu, Magar, Tamang, Bhote, Newar, Sherpa

Table 1: Caste of the vulnerable community of the year 2076-2077

\begin{tabular}{|l|l|l|}
\hline Caste & Male/Boys & Female/Girls \\
\hline Brahmin & 0 & 10 \\
\hline Chettri & 8 & 38 \\
\hline Janjati & 6 & 96 \\
\hline Dalit & 0 & 35 \\
\hline Madhesi & 0 & 9 \\
\hline Thakuri & 0 & 3 \\
\hline
\end{tabular}

Source: Nepal Police, Human Trafficking Bureau, Kathmandu 
Table 2: Caste of the vulnerable community of the year 2077-2078

\begin{tabular}{|l|l|l|}
\hline Caste & Boys/Male & Girls/Female \\
\hline Brahmin & 0 & 1 \\
\hline Chettri & 0 & 7 \\
\hline Janjati & 0 & 6 \\
\hline Dalit & 0 & 1 \\
\hline Madhesi & 0 & 2 \\
\hline Thakuri & 0 & 0 \\
\hline
\end{tabular}

Source: Nepal Police, Human Trafficking Bureau, Kathmandu

Table 3: Age group of the victims of the year 2076-2077

\begin{tabular}{|l|l|l|}
\hline Age Group & Boys/Male & Girls/Female \\
\hline 10 and less & 1 & 0 \\
\hline 11 years & 1 & 45 \\
\hline $17-18$ years & 2 & 25 \\
\hline $19-25$ years & 2 & 81 \\
\hline $26-35$ years & 6 & 26 \\
\hline $36-45$ years & 1 & 9 \\
\hline 46 and above & 2 & 1 \\
\hline
\end{tabular}

Source: Nepal Police, Human Trafficking Bureau, Kathmandu

Table 4: Age group of the victims of the year 2077-2078

\begin{tabular}{|l|l|l|}
\hline Age group & Boys/Male & Girls/Female \\
\hline 10 and less & 0 & 0 \\
\hline 11 years & 0 & 6 \\
\hline $17-18$ years & 0 & 5 \\
\hline $19-25$ years & 0 & 5 \\
\hline $26-35$ years & 0 & 0 \\
\hline $36-45$ years & 0 & 2 \\
\hline 46 and above & 0 & 0 \\
\hline
\end{tabular}

Source: Nepal Police, Human Trafficking Bureau, Kathmandu

\section{Factors responsible for Human trafficking in Nepal:}

- Labour Migration - Many people migrate from rural areas to urban cities in order to earn money to lead a happy life. In this process big contractors recruit them in different industries by making false promises and they become vulnerable to trafficking. Nepali women who are trafficked to the gulf countries by fraudulent companies face poor health conditions.

- Poverty - In Nepal most of the people depend on agriculture for living but due to geographical terrain and natural calamities many people migrate to the cities or to the foreign land in search of better job. This makes the job of the traffickers very easy.

- Lack of Education - Literacy rate of female is 59.72\% and male is $78.59 \%$. This shows that females are not still considered to be equal to men in terms of education also. This patriarchal society does not allow women to study and they are left with other options to earn money. So, they became more vulnerable to trafficking.

- Severe unemployment - Unemployment is the major factor for trafficking. Unskilled women and children are the easy target group for exploitation. People are trafficked by promising a better life abroad or in the big cities.

- Political Instability - Political stability in the country is one of the biggest reasons for economic growth and development but due to political turmoil it ultimately leads to high rate of unemployment. This will further lead to high rates of crimes like trafficking.

- Gender discrimination - In a patriarchal society like Nepal women condition is worse. Illiteracy, unemployment among women makes them the victims of domestic violence. They are dependent upon men for their livelihood. Illiteracy and unemployment among 
women make them the victims of domestic violence like physical and mental torture, emotional insults, inadequate food, excessive workload, restrictions on social relations make them vulnerable.

- $\quad$ Natural disaster - In 2015 in Nepal the earthquake killed 9000 people, demolished 6000 homes and made three million people homeless. The human traffickers tried to abduct children who had lost their parents in the quake and has sent hundreds of young women from earthquake hit areas of Nepal to the gulf, where they were forced into manual labour and sex work.

The poor people in Nepal are also targeted by organ traffickers who offered quick cash for people willing to sell their kidneys.

- $\quad$ Porous Border - Nepal shares about $1850 \mathrm{~km}$ long porous border with five Indian states-Uttarakhand, Uttar Pradesh, Bihar, West Bengal and Sikkim. According to Raju Aryal, Deputy Inspector General of the Armed Police Force (APF) more than 22,000 APF personnel are posted along the India-Nepal border at nearly 1,200 border outposts. But still the trafficking cases are increasing day by day because traffickers used different sources of medium like fake travel document or medical documents which shows that the women or girls are being taken to the Indian cities for medical treatment.

- Culture - Tamang community in Nepal spend excessively on certain feast and festivals like gharpaicho (new house). They need a large quantity of grain to make alcohol. Another tradition is Ghewa which is a funeral procession. Society hates the family who is unable to conduct the ghewa appropriately. Sometimes they have to sell their property because a lot of money is spent in ghewa. These feasts increases the chances of trafficking because the money left will be insufficient for running the house.

- Child marriage -It is still prevalent in some culture in tarai and hill region which make the situation more vulnerable for the young girls. Early marriage leads to early child birth, drop out from the school, dependent on the husband for the financial expenses, face domestic violence. In order to earn a respect in the family the young girls often choose the road which ultimately leads them to being trafficked by the traffickers. Sometimes husbands abandon their first wife and children to marry the other woman. Due to illiteracy and lack of skills those girls/women indulge in prostitution to earn a living for themselves or for their children.

- Governance - Traffickers are protected by the political parties. Even when police catches hold of the traffickers they are freed through influential friends at the national level. Sometimes even the corrupt police personnel set them free after receiving a high amount of bribe.

- Dysfunctional family - Many young girls/boys migrated to urban area due to stepparent's physical torture, domestic violence, sexual abuse, beating, no food at home, fail to go to school, thrown out of their houses. These children become more vulnerable to trafficking and sexual exploitation.
- Availability and use of drugs - A study was carried out by the National Centre for AIDS and STD Control, Ministry of Health, Nepal in 2016 to examine the biological and behavioural surveillance among female drug users in Kathmandu valley found out that $30 \%$ of women/young girls had sex before they reached 15 years of age. The ones who are addicted to drugs keep sexual relations to those people who can provide them drugs or money. These women/young girls are at risks of trafficking.

- Remittances - It is one of the important sources of household income which somehow contributed to human trafficking as majority of the unskilled labour migrates to gulf countries where they become more vulnerable to exploitation.

- Relaxed pre- departure screening - The networks of the traffickers are so powerful that they infiltrate the immigration department. Traffickers have managed to establish a system where these obligatory procedures have been breached.

- Undocumented migration -Many people are taken from India's sea route to different parts of the world by using forged documents or through irregular channel which makes them more vulnerable to human trafficking.

- Unprotected Children- The children who are orphans or who live on the streets are the most vulnerable in the society. Street children are negatively viewed and stigmatized by many people and often labelled with the derogatory term" Khate". They become the easy victim of human trafficking as they can be easily lured by the brokers or traffickers.

- Too much documentation - A prospective migrant worker has to prepare number of documents which makes it impossible to complete the whole process without depending on the services of agents and middlemen. Migrant worker coming from outside the Kathmandu valley cannot afford to stay for so long to prepare the required documents. The only option is to look for shortcuts which makes them vulnerable to human trafficking.

\section{Purpose of Human Trafficking:}

The purpose of human trafficking is different depending upon the demand in the market.

1) Slavery - Slavery still exists in the form of bounded labour where the victims serve the owners as the guarantee of loans. Nepal has been affected from generation-to-generation bonded labour and other forms of servitude under such system as Kamaiya, Haliya, Bhude, Kamalari, Haruwa -Charuwa, Baalighare (Khalo), Dom, Pode, Badi and Deuki. The practice is particularly prevalent in the far western region which has the highest concentration of big land. Females bonded labour are more vulnerable to exploitation, physical assault and rape in patriarchal and feudal society. Although the government has banned all these practices but it is still rampant. 
2) Forced Labours - Almost all the victims are trafficked by making false promises of better employment opportunities in big cities. Illiteracy and poor condition of the women make them more vulnerable and they are force to work as force labour and face sexual and physical abuse at the hands of the owner. Children are forced to work as domestic helpers and commercial labours.

3) Organ Trade - This is new business in the field of human trafficking. Due to increase in demand of kidney young teenagers and children are being trafficked and their body parts are taken out. Even sometimes poor people in Nepal sell their kidney for a very small amount of money with no further medical care.

4) Sexual Exploitation - Women and young girls have to work in inhumane condition in the brothel and they are under surveillance all the time. They face death threats and live in the constant fear of the traffickers. Sex workers are often subjected to unwanted pregnancies because customer pay huge money to the Dalal for having sex without protection. Due to this many have contracted HIV and other sexually transmitted disease (STD). They are often denied of the medical care which further worsens their health condition.

5) Entertainment sector - Many girls/women migrate to Kathmandu valley in search of employment and money. They mainly work in the restaurants and dance bars. Most of them are uneducated. Due to illiteracy and economic hardship the young girls and women easily slip into exploitation and vulnerable towards being trafficked. Shakti Samuha an NGO in Nepal organized a workshop in 2014 and found out that there was an increase in the visit of the agents to the restaurants and dance bars to lure girls/women for going abroad by making false promises of good employment opportunity.

6) Forced Marriage - Due to low sex ration in India, China and South Korea the girls and women from Nepal are being trafficked to these countries where they are forcefully married and are maltreated. There are many fake marriage bureaus which are operating in Nepal that lure the young girls into paper marriages with Korean and Chinese men twice their age. Due to unemployment and economic hardship young girls and women from the rural areas become the easy targets for trafficking. Many women and girls are trapped in slavery like condition where they are abused physically and sexually, mentally tortured and are not properly fed.

7) Street begging - Many young girls and boys are trafficked and made to beg on the streets deliberately by making them crippled. Traffickers use children as begging "props" to maximise their earnings from sympathetic passers-by.

\section{CONSEQUENCES OF TRAFFICKING:}

There are several negative consequences of trafficking which has been mentioned in various literature. According to Zimmerman (2009) the hazardous conditions in which the victims are trafficked into or even the conditions they are in when some manage to escape leave them in tremendous health risks.

- HIV/AIDS Disease - Many girls/women who were rescued from the brothels suffered from HIV/AIDS and other STD diseases. In many cases women working as sex workers have to entertain many male clients and they have intercourse without protection. This leaves them vulnerable to the deadly disease HIV/AIDS or other sexually transmitted diseases.

- Physical Health - Many victims have shared that while in prostitutions they were subjected to physical violence at the hands of the clients. If they got pregnant then the pimp used to kick and punch them in their bellies in order to terminate their pregnancy. Sometimes due to heavy loss of blood many women and young girls became unconscious and weak. The victims used to be physically assaulted like burning them with cigarette, beating them with belts and beer bottles and do vaginal torture by inserting the sharp knife inside the vagina by the pimp if they refused to have sex with the customers.

- Psychological Health - A study done by Retina Rimal \& et.al. in 2016 found that victims of sex trafficking in Nepal scored high on anxiety, depression and Post Traumatic Stress Disorder (PTSD).

\section{RECOMMENDATION:}

- Due to the open border, it becomes easy for the traffickers to trafficked the poor and vulnerable women and young girls. Detailed inquiry of the travellers should be done at every border check point in Nepal.

- Organizations who are working actively against trafficking should reach the prostitute women in the Indian brothels with the help of Indian Police. The sex workers should be provided proper counselling to rescue them from the prostitution.

- More rehabilitation centres should be opened for women who are trafficked in each district. This will help the victims to reach for the treatment. The rehabilitation centre should provide proper counselling to the victims and also medical treatment free of cost.

- Government should provide housing facilities for the trafficked survivors. This will reduce the chances of women being homeless or return to the prostitution.

- Laws should be made for free and compulsory education to every girl and boy till 18 years of age. Scholarship, school uniform, better transportation facilities, stationary items should be provided to the children to help them to enrol in the school.

- Several studies have revealed that due to the fear of punishment many children drop out of the school and this makes them vulnerable to trafficking. The government should make laws against the corporal punishment. 
- Vocational training should be provided to each and every child in the school.

- Government and the NGOs who are working against trafficking and gender-based violence should show movies and documentaries based on girl's education, human trafficking, human rights, gender issues to the villagers in order to educate and sensitize them about these issues.

- Child marriage, remarriage, multiple marriages and unmatched marriage practices increases the young girls/women vulnerability to trafficking for commercial sexual exploitation in some community. The marriage law should be redesigned and made effective.

- Several projects and training should be provided to women like agro-based, computer training, tailoring, beauty salons, driving lessons etc so that they can earn a livelihood in the village only.

- More advertisement and news regarding trafficking issues should be broadcasted in all the TV and radio channels.

- Strict policies should be made by the government regarding the kidney surgery. This will help in curbing the illegal transplantation of Kidney.

- Government should start providing mid-day meal to the poor students in every district. This will help in keeping the children enrolled in the school and this will reduce the chances of their vulnerability to trafficking.

- Street plays should be performed by the organizations fighting against human trafficking to make the public aware of the trafficking issues.

- The government of Nepal should adopt the UN Special Rapporteur's definition of trafficking that will protect the rights of all trafficked persons, including those who are trafficked for purposes other than prostitution like forced labour, pornography, slavery.

- Media should talk about the trafficking issues openly so that people are aware of what is happening around them.

- The state should provide soft loans, infrastructural support and educational scholarships to women, including women who have been or are engaged in prostitution.

\section{ACKNOWLEDGEMENTS}

I would like to thank Mr. Shambhu Subedi, DIG, Armed Police Force (APF), Nepal and Mr. Tanka Bhattrai, DSP, Nepal Police, Nepal for providing their expertise and assistance in this study.

\section{FUNDING SOURCES}

None

\section{COMPETING INTERESTS}

No competing interests exist

\section{REFERENCES}

[1] Datta, P. (2005). Nepali female migration and trafficking. Journal of Social Science, 11(1), 49-56.

[2] Evans, C., \& Bhattarai, P. (2000). Trafficking in Nepal: Intervention models a comparative analysis of anti-trafficking intervention approaches in Nepal.

[3] Hennink, M., \& Simkhada, P. (2004). Sex trafficking in Nepal: context and process. Asian and Pacific Migration Journal, 13(3), 305-338.

[4] Joshi, S. (2010). Human trafficking in Nepal: A rising concern for all. Kathmandu University Medical Journal, 8(29),3-4.

[5] Kc, Bal \& Subedi, Govind \& Gurung, Yogendra \& Keshab, Gurung \& Adhikari, Prasad. (2001). Trafficking in Girls with Special Reference to Prostitution: A Rapid Assessment.

[6] International Labour Office; IPEC and DPDS of Tribhuvan University, Nepal

[7] Nair, P. M. \& Sankar Sen (2005); Trafficking in women and children in India; National Human Rights Commission; Orient Longman Publication Pvt. Ltd.; New Delhi

[8] Troubnikoff, A.M. (2003). Trafficking in women and children: current issues and developments.

[9] Tsutsumi, A., Izutsu, T., Poudyal, A. K., Kato, S., \& Marui, E. (2008). Mental health of female survivors of human trafficking in Nepal. Social Science \& Medicine, 66(8), 1841-1847.

\section{AUTHORS}

First Author - Kavita Thapa, Counsellor, D.A.V Public School, Sector-14, Gurugram, Email: kavitathapa10@gmail.com 